\title{
Coupled coincidence point theorems for generalized nonlinear contraction in partially ordered metric spaces
}

\author{
Hui-Sheng Ding ${ }^{1 *}$, Lu Li ${ }^{1}$ and Stojan Radenović ${ }^{2}$
}

\author{
* Correspondence: dinghs@mail. \\ ustc.edu.cn \\ ${ }^{1}$ College of Mathematics and \\ Information Science, Jiangxi \\ Normal University, Nanchang, \\ Jiangxi 330022, People's Republic \\ of China \\ Full list of author information is \\ available at the end of the article
}

\begin{abstract}
This paper is concerned with mixed g-monotone mappings in partially ordered metric spaces. We establish several coupled coincidence and coupled common fixed point theorems, which generalize and complement some known results. Especially, our main results complement some recent results due to Lakshmikantham and Ćirić. Two examples are given to illustrate the usability of our results.

Mathematics Subject Classification(2010): 47H10, 54H 25.

Keywords: coupled coincidence, coupled common fixed point, mixed g-monotone, partially ordered, metric space
\end{abstract}

\section{Introduction}

The existence of fixed points for monotone mappings in partially ordered metric spaces was initialed in [1], and such problems have been of great interest for many mathematicians (see, e.g, [2-6] and references therein).

The existence of coupled fixed points for mixed monotone mappings in partially ordered metric spaces was firstly studied by Bhaskar and Lakshmikantham [7], where some applications to periodic boundary value problems are studied. Since then, several authors have made contributions on such problems (see, e.g., [8-16]). Especially, Lakshmikantham and Ćirić [13] introduced a new concept of mixed g-monotone mapping:

Definition 1.1. Let $(X, \leq)$ be a partially ordered set, $F: X \times X \rightarrow X$ and $g: X \rightarrow X$. We say $F$ has the mixed g-monotone property if $F$ is monotone $g$-non-decreasing in its first argument and is monotone $g$-non-increasing in its second argument, that is, for any $x$, $y \in X$,

$$
x_{1}, x_{2} \in X, g\left(x_{1}\right) \leq g\left(x_{2}\right) \quad \text { implies } \quad F\left(x_{1}, y\right) \leq F\left(x_{2}, y\right),
$$

and

$$
y_{1}, y_{2} \in X, g\left(y_{1}\right) \leq g\left(y_{2}\right) \text { implies } F\left(x, y_{1}\right) \geq F\left(x, y_{2}\right) .
$$

Moreover, Lakshmikantham and Ćirić [13] established several coupled coincidence and coupled fixed point theorems for mixed g-monotone mappings in a partially ordered metric space. In [13], one of the key assumption on the mixed g-monotone mapping $F$ is:

(c) 2012 Ding et al; licensee Springer. This is an Open Access article distributed under the terms of the Creative Commons Attribution License (http://creativecommons.org/licenses/by/2.0), which permits unrestricted use, distribution, and reproduction in any medium, provided the original work is properly cited. 


$$
d(F(x, y), F(u, v)) \leq \varphi\left(\frac{d(g(x), g(u))+d(g(y), g(v))}{2}\right)
$$

for all $x, y, u, v \in X$ with $g(x) \leq g(u)$ and $g(y) \geq g(v)$, where $\phi:[0,+\infty) \rightarrow[0,+\infty)$ satisfies $\phi(t)<$ and $\lim _{r \rightarrow t+} \varphi(t)<t$ for each $t>0$.

The aim of this paper is to extend and complement the main results in [13] by replacing the contraction assumption (1.1) by a more general condition (see (A1) in Theorem 1). As one will see, our main results are generalizations and complements of some earlier results (see Examples and Remark 1). For some details see $[17,18]$.

\section{Main results}

Throughout the rest of this paper, we denote by $\mathbb{N}$ the set of positive integers, and by $(X, \leq, d)$ a complete partially ordered metric space, i.e., $\leq$ is a partial order on the set $X$, and $d$ is a complete metric on $X$. Moreover, we endow the product space $X \times X$ with the following partial order: $(u, v) \leq(x, y) \Leftrightarrow x \geq u, y \leq v$.

Now, let us present one of our main results.

Theorem 2.1. Assume that $g: X \rightarrow X$ is a continuous mapping, and $F: X \times X \rightarrow X$ is a continuous mapping with the mixed $g$-monotone property on $X$. Suppose that the following assumptions hold:

(A1) there exists a non-decreasing function $\varphi:[0,+\infty) \rightarrow[0,+\infty)$ such that $\lim _{n \rightarrow \infty} \phi^{n}(t)=0$ for each $t>0$, and $d(F(x, y), F(u, v)) \leq \varphi\left[M_{F, g}(x, y, u, v)\right]$ for all $x, y, u, v \in$ $X$ with $g x \geq g u$ and $g y \leq g v$, where

$$
\begin{aligned}
M_{F, g}(x, y, u, v)= & \max \{d(g x, g u), d(g y, g v), d(g x, F(x, y)), d(g u, F(u, v)), d(g y, F(y, x)), d(g v, F(v, u)), \\
& \left.\frac{d(g x, F(u, v))+d(g u, F(x, y))}{2}, \frac{d(g y, F(v, u))+d(g v, F(y, x))}{2}\right\} .
\end{aligned}
$$

(A2) there exist $x_{0}, y_{0} \in X$ such that $g x_{0} \leq F\left(x_{0}, y_{0}\right)$ and $F\left(y_{0}, x_{0}\right) \leq g y_{0}$;

(A3) $F(X \times X) \subseteq g(X)$, and $g$ and $F$ are commuting, i.e., $g(F(x, y))=F(g x, g y)$ for all $x, y \in X$.

Then $F$ and $g$ have a coupled coincidence point, i.e., there exist $x_{*}, y_{*} \in X$ such that $F$ $\left(x_{*}, y_{*}\right)=g x_{*}$ and $F\left(y_{*}, x_{*}\right)=g y_{*}$.

Proof. First, we claim that $\varphi(t)<t$ for each $t>0$. In fact, if $\varphi\left(t_{0}\right) \geq t_{0}$ for some $t_{0}>0$, then, since $\varphi$ is non-decreasing, $\varphi^{n}\left(t_{0}\right) \geq t_{0}$ for all $\mathbb{N}$, which contradicts with $\lim _{n \rightarrow \infty} \phi^{n}\left(t_{0}\right)=0$. In addition, it is easy to see that $\varphi(0)=0$. Since $F(X \times X) \subseteq g(X)$, one can construct two sequences $\left\{x_{n}\right\},\left\{y_{n}\right\}$ in $X$ such that $g x_{n}=F\left(x_{n-1}, y_{n-1}\right), g y_{n}=F\left(y_{n-1}, x_{n-}\right.$ $\left.{ }_{1}\right), n \in \mathbb{N}$. Observing that $F$ has the mixed $g$-monotone property on $X$, by (A2), we get $g x_{0} \leq g x_{1} \leq \ldots \leq g x_{n} \leq g x_{n+1} \leq \ldots$ and $\ldots \leq g y_{n+1} \leq g y_{n} \leq \ldots \leq g y_{1} \leq g y_{0}$.

Now, by (A1), we have

$$
d\left(g x_{n+1}, g x_{n}\right)=d\left(F\left(x_{n}, y_{n}\right), F\left(x_{n-1}, y_{n-1}\right)\right) \leq \phi\left(M_{F, g}\left(x_{n}, y_{n}, x_{n-1}, y_{n-1}\right)\right),
$$

and

$$
d\left(g y_{n}, g y_{n+1}\right)=d\left(F\left(y_{n-1}, x_{n-1}\right), F\left(y_{n}, x_{n}\right)\right) \leq \phi\left(M_{F, g}\left(y_{n-1}, x_{n-1}, y_{n}, x_{n}\right)\right),
$$


where

$$
\begin{aligned}
& M_{F, g}\left(x_{n}, y_{n}, x_{n-1}, y_{n-1}\right)=M_{F, g}\left(y_{n-1}, x_{n-1}, y_{n}, x_{n}\right) \\
&= \max \left\{d\left(g x_{n}, g x_{n-1}\right), d\left(g y_{n}, g y_{n-1}\right), d\left(g x_{n}, F\left(x_{n}, y_{n}\right)\right), d\left(g x_{n-1}, F\left(x_{n-1}, y_{n-1}\right)\right),\right. \\
& d\left(g y_{n}, F\left(y_{n}, x_{n}\right)\right), d\left(g y_{n-1}, F\left(y_{n-1}, x_{n-1}\right)\right), \frac{d\left(g x_{n}, F\left(x_{n-1}, y_{n-1}\right)\right)+d\left(g x_{n-1}, F\left(x_{n}, y_{n}\right)\right),}{2} \\
&\left.\frac{d\left(g y_{n}, F\left(y_{n-1}, x_{n-1}\right)\right)+d\left(g y_{n-1}, F\left(y_{n}, x_{n}\right)\right)}{2}\right\} \\
&= \max \left\{d\left(g x_{n}, g x_{n-1}\right), d\left(g y_{n}, g y_{n-1}\right), d\left(g x_{n}, g x_{n+1}\right), d\left(g y_{n}, g y_{n+1}\right),\right. \\
&\left.\frac{d\left(g x_{n-1}, g x_{n+1}\right)}{2}, \frac{d\left(g y_{n-1}, g y_{n+1}\right)}{2}\right\} .
\end{aligned}
$$

Next, let us consider five cases.

Case I. $M_{F, g}\left(x_{n}, y_{n}, x_{n-1}, y_{n-1}\right)=\max \left\{d\left(g x_{n}, g x_{n-1}\right), d\left(g y_{n}, g y_{n-1}\right)\right\}$.

We have

$$
d\left(g x_{n+1}, g x_{n}\right) \leq \phi\left[\max \left\{d\left(g x_{n}, g x_{n-1}\right), d\left(g y_{n}, g y_{n-1}\right)\right\}\right],
$$

and

$$
d\left(g y_{n}, g y_{n+1}\right) \leq \phi\left[\max \left\{d\left(g x_{n}, g x_{n-1}\right), d\left(g y_{n}, g y_{n-1}\right)\right\}\right] .
$$

Case II. $M_{F, g}\left(x_{n}, y_{n}, x_{n-1}, y_{n-1}\right)=d\left(g x_{n}, g x_{n+1}\right)$.

We claim that $M_{F, g}\left(x_{n}, y_{n}, x_{n-1}, y_{n-1}\right)=d\left(g x_{n}, g x_{n+1}\right)=0$. In fact, if $d\left(g x_{n}, g x_{n+1}\right) \neq 0$, then $d\left(g x_{n+1}, g x_{n}\right) \leq \varphi\left[d\left(g x_{n+1}, g x_{n}\right)\right]<d\left(g x_{n+1}, g x_{n}\right)$, which is contradiction. Since $M_{F, g}$ $\left(x_{n}, y_{n}, x_{n-1}, y_{n-1}\right)=0$, we also have $d\left(g y_{n}, g y_{n+1}\right)=0$. Then, it is obvious that (2.1) and (2.2) hold.

Case III. $M_{F, g}\left(x_{n}, y_{n}, x_{n-1}, y_{n-1}\right)=d\left(g y_{n}, g y_{n+1}\right)$.

Similar to the proof of Case II, one can also show that (2.1) and (2.2) hold.

Case IV. $M_{F, g}\left(x_{n}, y_{n}, x_{n-1}, y_{n-1}\right)=\frac{d\left(g x_{n-1}, g x_{n+1}\right)}{2}$.

We also claim that $d\left(g x_{n-1}, g x_{n+1}\right)=0$. In fact, if $d\left(g x_{n-1}, g x_{n+1}\right) \neq 0$, then

$$
\begin{aligned}
d\left(g x_{n+1}, g x_{n}\right) & \leq \phi\left[\frac{d\left(g x_{n-1}, g x_{n+1}\right)}{2}\right] \\
& <\frac{d\left(g x_{n-1}, g x_{n+1}\right)}{2} \\
& \leq \frac{d\left(g x_{n-1}, g x_{n}\right)}{2}+\frac{d\left(g x_{n}, g x_{n+1}\right)}{2},
\end{aligned}
$$

which gives that $d\left(g x_{n+1}, g x_{n}\right)<d\left(g x_{n-1}, g x_{n}\right)$. Thus,

$$
M_{F}\left(x_{n}, y_{n}, x_{n-1}, y_{n-1}\right)=\frac{d\left(g x_{n-1}, g x_{n+1}\right)}{2}<d\left(g x_{n-1}, g x_{n}\right),
$$

which contradicts with the definition of $M_{F}\left(x_{n}, y_{n}, x_{n-1}, y_{n-1}\right)$. So

$$
M_{F}\left(x_{n}, y_{n}, x_{n-1}, y_{n-1}\right)=\frac{d\left(g x_{n-1}, g x_{n+1}\right)}{2}=0 .
$$

Thus, $d\left(g x_{n}, g x_{n+1}\right)=d\left(g y_{n}, g y_{n+1}\right)=0$, which means that (2.1) and (2.2) hold.

Case V. $M_{F, g}\left(x_{n}, y_{n}, x_{n-1}, y_{n-1}\right)=\frac{d\left(g y_{n-1}, g y_{n+1}\right)}{2}$.

By using a similar argument to Case IV, one can also show that (2.1) and (2.2) hold. Now, by (2.1) and (2.2), we have for all $n \in \mathbb{N}$, 


$$
\begin{aligned}
& \max \left\{d\left(g x_{n+1}, g x_{n}\right), d\left(g y_{n}, g y_{n+1}\right)\right\} \\
\leq & \left.\phi\left[\max \left\{d\left(g x_{n}, g x_{n-1}\right), d\left(g y_{n}, g y_{n-1}\right)\right)\right\}\right] \\
\leq & \left.\phi^{n}\left[\max \left\{d\left(g x_{1}, g x_{0}\right), d\left(g y_{1}, g y_{0}\right)\right)\right\}\right] .
\end{aligned}
$$

Let $\varepsilon>0$ be fixed. Without loss of generality, one can assume that

$$
\left.\max \left\{d\left(g x_{1}, g x_{0}\right), d\left(g y_{1}, g y_{0}\right)\right)\right\} \neq 0 .
$$

In fact, if this is not true, then

$$
g x_{0}=g x_{1}=F\left(x_{0}, y_{0}\right), \quad g y_{0}=g y_{1}=F\left(y_{0}, x_{0}\right),
$$

i.e., $x_{0}, y_{0}$ is a coupled coincidence point of $F$ and $g$. Since $\lim _{n \rightarrow \infty} \varphi^{n}(t)=0$ for each $t>0$, by using (2.3), there exists $N \in \mathbb{N}$ such that for all $n>N$,

$$
\max \left\{d\left(g x_{n+1}, g x_{n}\right), d\left(g y_{n}, g y_{n+1}\right)\right\}<\varepsilon-\phi(\varepsilon) .
$$

Next, let us prove that for all $n>N$,

$$
\max \left\{d\left(g x_{n+p}, g x_{n}\right), d\left(g y_{n}, g y_{n+p}\right)\right\} \leq \varepsilon, \forall p \in \mathbb{N},
$$

and

$$
\max \left\{d\left(g x_{n+p-1}, g x_{n+1}\right), d\left(g y_{n+1}, g y_{n+p-1}\right)\right\} \leq \phi(\varepsilon), \forall p \geq 3 .
$$

For $p=1$, it follows directly from (2.4) that (2.5) holds. For $p=2$, (2.5) follows from

$$
\begin{aligned}
& \max \left\{d\left(g x_{n+2}, g x_{n}\right), d\left(g y_{n+2}, g y_{n}\right)\right\} \\
\leq & \max \left\{d\left(g x_{n+2}, g x_{n+1}\right), d\left(g y_{n+2}, g y_{n+1}\right)\right\}+\max \left\{d\left(g x_{n+1}, g x_{n}\right), d\left(g y_{n+1}, g y_{n}\right)\right\} \\
\leq & \phi\left[\max \left\{d\left(g x_{n+1}, g x_{n}\right), d\left(g y_{n+1}, g y_{n}\right)\right\}\right]+\varepsilon-\phi(\varepsilon) \\
\leq & \phi(\varepsilon)+\varepsilon-\phi(\varepsilon)=\varepsilon,
\end{aligned}
$$

where (2.3) and (2.4) are used. Let us show that (2.5) and (2.6) hold for $p=3$. Firstly, by (2.3) and (2.4), we have

$$
\max \left\{d\left(g x_{n+2}, g x_{n+1}\right), d\left(g y_{n+2}, g y_{n+1}\right)\right\} \leq \phi\left[\max \left\{d\left(g x_{n+1}, g x_{n}\right), d\left(g y_{n+1}, g y_{n}\right)\right\}\right] \leq \phi(\varepsilon),
$$

which means that (2.6) holds for $p=3$. Secondly, by (A1), we have

$$
\max \left\{d\left(g x_{n+3}, g x_{n+1}\right), d\left(g y_{n+1}, g y_{n+3}\right)\right\} \leq \phi\left[z_{n}\right],
$$

where

$$
\begin{aligned}
z_{n}= & \max \left\{d\left(g x_{n+2}, g x_{n}\right), d\left(g y_{n}, g y_{n+2}\right), d\left(g x_{n+2}, g x_{n+3}\right), d\left(g y_{n+2}, g y_{n+3}\right), d\left(g x_{n}, g x_{n+1}\right), d\left(g y_{n}, g y_{n+1}\right),\right. \\
& \left.\frac{d\left(g x_{n+2}, g x_{n+1}\right)+d\left(g x_{n}, g x_{n+3}\right)}{2}, \frac{d\left(g y_{n+2}, g y_{n+1}\right)+d\left(g y_{n}, g y_{n+3}\right)}{2}\right\} .
\end{aligned}
$$

We claim that $z_{n} \leq \varepsilon$. In fact, if $z_{n}=\max \left\{d\left(g x_{n+2}, g x_{n}\right), d\left(g y_{n}, g y_{n+2}\right)\right\}$, then by (2.5) $(p=2), z_{n} \leq \varepsilon$; if $z_{n}=\max \left\{d\left(g x_{n+2}, g x_{n+3}\right), d\left(g y_{n+2}, g y_{n+3}\right)\right\}$, then by (2.3) and (2.4), $z_{n} \leq \varphi^{2}(\varepsilon) \leq \varepsilon$; if $z_{n}=\max \left\{d\left(g x_{n}, g x_{n+1}\right), d\left(g y_{n}, g y_{n+1}\right)\right\}$, then (2.4) gives that $z_{n} \leq \varepsilon$; if $z_{n}=\frac{d\left(g x_{n+2}, g x_{n+1}\right)+d\left(g x_{n}, g y_{n+3}\right)}{2}$, then by (2.7), there holds $d\left(g x_{n+3}, g x_{n+1}\right) \leq \frac{d\left(g x_{n+2}, g x_{n+1}\right)+d\left(g x_{n}, g y_{n+3}\right)}{2} \leq \frac{\phi(\varepsilon)+d\left(g x_{n}, g y_{n+3}\right)}{2}$, which yields that 


$$
\begin{aligned}
d\left(g x_{n}, g x_{n+3}\right) & \leq d\left(g x_{n+3}, g x_{n+1}\right)+d\left(g x_{n+1}, g x_{n}\right) \\
& \leq \frac{\phi(\varepsilon)+d\left(g x_{n}, g x_{n+3}\right)}{2}+\varepsilon-\phi(\varepsilon) \\
& =\varepsilon-\frac{\phi(\varepsilon)}{2}+\frac{d\left(g x_{n}, g x_{n+3}\right)}{2},
\end{aligned}
$$

and $\quad$ thus, $\quad z_{n}=\frac{d\left(g x_{n+2}, g x_{n+1}\right)+d\left(g x_{n}, g x_{n+3}\right)}{2} \leq \frac{\phi(\varepsilon)}{2}+\frac{d\left(g x_{n}, g x_{n+3}\right)}{2} \leq \varepsilon ; \quad$ if $z_{n}=\frac{d\left(g \gamma_{n+2}, g y_{n+1}\right)+d\left(g y_{n}, g y_{n+3}\right)}{2}$, one can similarly show that $z_{n} \leq \varepsilon$. Hence, in all cases, $z_{n} \leq \varepsilon$. Then, by (2.4) and (2.7), we get

$$
\begin{aligned}
& \max \left\{d\left(g x_{n+3}, g x_{n}\right), d\left(g y_{n}, g y_{n+3}\right)\right\} \\
\leq & \max \left\{d\left(g x_{n+3}, g x_{n+1}\right), d\left(g y_{n+1}, g y_{n+3}\right)\right\}+\max \left\{d\left(g x_{n+1}, g x_{n}\right), d\left(g y_{n}, g y_{n+1}\right)\right\} \\
\leq & \phi(\varepsilon)+\varepsilon-\phi(\varepsilon)=\varepsilon
\end{aligned}
$$

i.e., (2.5) holds for $p=3$.

Now, suppose that (2.5) and (2.6) hold for all $p \leq k-1$. Let us prove that (2.5) and (2.6) hold for $p=k$. By (A1), (2.3), (2.4), (2.5) for $p=k-2, k-1$ and for $p=k-1$ we conclude

$$
\begin{aligned}
& \max \left\{d\left(g x_{n+k-1}, g x_{n+1}\right), d\left(g y_{n+1}, g y_{n+k-1}\right)\right\} \\
& \leq \phi\left[\operatorname { m a x } \left\{d\left(g x_{n+k-2}, g x_{n}\right), d\left(g y_{n}, g y_{n+k-2}\right), d\left(g x_{n+k-2}, g x_{n+k-1}\right), d\left(g y_{n+k-2}, g y_{n+k-1}\right)\right.\right. \text {, } \\
& d\left(g x_{n}, g x_{n+1}\right), d\left(g y_{n}, g y_{n+1}\right), \frac{d\left(g x_{n+k-2}, g x_{n+1}\right)+d\left(g x_{n}, g x_{n+k-1}\right)}{2}, \\
& \left.\left.\frac{d\left(g y_{n+k-2}, g y_{n+1}\right)+d\left(g y_{n}, g y_{n+k-1}\right)}{2}\right\}\right] \\
& \leq \phi\left[\max \left\{\varepsilon, \phi^{k-2}(\varepsilon), \frac{\phi(\varepsilon)+\varepsilon}{2}\right\}\right] \leq \phi(\varepsilon),
\end{aligned}
$$

i.e., (2.6) holds for $p=k$. In addition, since $\max \left\{d\left(g x_{n+k}, g x_{n+1}\right), d\left(g y_{n+1}, g y_{n+k}\right)\right\} \leq \varphi$ $\left[w_{n}\right]$, where $w_{n}=\max \left\{d\left(g x_{n+k-1}, g x_{n}\right), d\left(g y_{n}, g y_{n+k-1}\right), d\left(g x_{n+k-1}, g x_{n+k}\right), d\left(g y_{n+k-1}, g y_{n+k}\right)\right.$, $d\left(g x_{n}, g x_{n+1}\right)$,

$$
\begin{gathered}
w_{n}=\max \left\{d\left(g x_{n+k-1}, g x_{n}\right), d\left(g y_{n}, g y_{n+k-1}\right), d\left(g x_{n+k-1}, g x_{n+k}\right), d\left(g y_{n+k-1}, g y_{n+k}\right), d\left(g x_{n}, g x_{n+1}\right),\right. \\
\left.\quad d\left(g y_{n}, g y_{n+1}\right), \frac{d\left(g x_{n+k-1}, g x_{n+1}\right)+d\left(g x_{n}, g x_{n+k}\right)}{2}, \frac{d\left(g y_{n+k-1}, g y_{n+1}\right)+d\left(g y_{n}, g y_{n+k}\right)}{2}\right\},
\end{gathered}
$$

by similar proof to that of $z_{n}$ (see (2.7)), one can show that $w_{n} \leq \varepsilon$. Thus,

$$
\begin{aligned}
& \max \left\{d\left(g x_{n+k}, g x_{n}\right), d\left(g y_{n}, g y_{n+k}\right)\right\} \\
\leq & \max \left\{d\left(g x_{n+k}, g x_{n+1}\right), d\left(g y_{n+1}, g y_{n+k}\right)\right\}+\max \left\{d\left(g x_{n+1}, g x_{n}\right), d\left(g y_{n}, g y_{n+1}\right)\right\} \\
\leq & \phi(\varepsilon)+\varepsilon-\phi(\varepsilon)=\varepsilon
\end{aligned}
$$

i.e., (2.6) holds for $p=k$.

Now, we have proved that (2.5) holds for all $p \in \mathbb{N}$, which means that $\left\{g x_{n}\right\}$ and $\left\{g y_{n}\right\}$ are Cauchy sequences in $X$. Then, by the completeness of $X$, there exist $x_{*}, y_{*} \in X$ such that $\lim _{n \rightarrow \infty} g x_{n}=x_{*}, \lim _{n \rightarrow \infty} g y_{n}=y_{* *}$. By (A3), $g$ commutes with $F$. So $g\left(g x_{n+1}\right)=g(F$ $\left.\left(x_{n}, y_{n}\right)\right)=F\left(g x_{n}, g y_{n}\right)$ and $g\left(g y_{n+1}\right)=g\left(F\left(y_{n}, x_{n}\right)\right)=F\left(g y_{n}, g x_{n}\right)$. Letting $n \rightarrow \infty$ and noticing that $F$ and $g$ are continuous, we get $g\left(x_{*}\right)=F\left(x_{*}, y_{*}\right), g\left(y_{*}\right)=F\left(y_{*}, x_{*}\right)$. 
We demonstrate the use of Theorems 2.1 with the help of the following examples. It will show also that our theorem is more general than some other known coupled fixed point results $([7,13])$

Examples: (1) Let $X=\mathbb{R}$ be endowed with usual order, $d(x, y)=|x-y|$, $F(x, y)=\frac{1}{4} x-\frac{1}{5} y, g x=\frac{1}{2} x, \phi(t)=\frac{9}{10} t$. We have that mappings $F, g$ and $\varphi$ satisfy all conditions of the Theorem 2.1, but they do not satisfy (1.1). Therefore $F$ and $g$ have a coupled coincidence point. Here $(0,0)$ is the coupled coincidence point of $F$ and $g$. Indeed, for $x \geq u, y \leq v$ we have

$$
\begin{aligned}
d(F(x, y), F(u, v))= & \left|\frac{1}{4}(x-u)+\frac{1}{5}(v-y)\right| \leq \frac{9}{20} \max \{|x-u|,|y-v|\} \\
& =\frac{9}{10} \max \left\{\left|\frac{x}{2}-\frac{u}{2}\right|,\left|\frac{y}{2}-\frac{v}{2}\right|\right\} \\
& =\frac{9}{10} \max \{d(g x, g u), d(g y, g v)\} .
\end{aligned}
$$

However, if (1.1) is true, then we have

$$
\frac{1}{4}=d\left(0, \frac{1}{4}\right)=d(F(0,0), F(1,0)) \leq \varphi\left(\frac{d(g 0, g 1)+d(g 0, g 0)}{2}\right)=\varphi\left(\frac{1}{4}\right)<\frac{1}{4}
$$

which is a contradiction. Hence, the existence of a coupled coincidence point of $F$ and $g$ cannot be obtained by the result from [13].

(2) If in the previous example we take $F(x, y)=\frac{1}{2} x-\frac{1}{3} y, g x=x, \phi(t)=\frac{5}{6} t$, then we obtain that mappings $F, g$ and $\varphi$ satisfy all conditions of the Theorem 2.1, but they do not satisfy the conditions of corresponding Theorem from [7]. Indeed, in this case we have

$$
d(F(x, y), F(u, v))=\left|\frac{1}{2}(x-u)+\frac{1}{3}(v-y)\right| \leq \frac{5}{6} \max \{|x-u|,|y-v|\} .
$$

On the other hand, for $x=1, y=u=v=0$, we obtain

$$
d(F(1,0), F(0,0))=\frac{1}{2}>\frac{k}{2}=\frac{k}{2}(d(1,0)+d(0,0)),
$$

for all $k \in[0,1)$. Also, this example shows that the existence of a coupled coincidence point of $F$ and $g$ cannot be obtained by the result from [7].

In the case that $F$ is not continuous, one can use the following theorem:

Theorem 2.2. Suppose all the assumptions of Theorem 2.1. except for the continuity of $F$ are satisfied. Moreover, assume that $g$ is monotone under the partial order $\leq$, and $X$ has the following properties:

(a) if an non-decreasing sequence $\left\{x_{n}\right\}$ converges to $X$ in $X$, then $x_{n} \leq x$ for all $n \in \mathbb{N}$;

(b) if an non-increasing sequence $\left\{y_{n}\right\}$ converges to $y$ in $X$, then $y \leq y_{n}$ for all $n \in \mathbb{N}$.

Then the conclusions of Theorem 2.1 also hold.

Proof. Let $\left\{x_{n}\right\},\left\{y_{n}\right\}, x_{*}, y_{*}$ be as in Theorem 1. Then $\lim _{n \rightarrow \infty} g x_{n}=x_{*}$ and $\lim _{n \rightarrow \infty}$ $g y_{n}=y_{*}$.

It remains to prove that $g\left(x_{*}\right)=F\left(x_{*}, y_{*}\right), g\left(y_{*}\right)=F\left(y_{*}, x_{*}\right)$.

By the proof of Theorem 1, we have $g x_{0} \leq g x_{1} \leq \ldots \leq g x_{n} \leq g x_{n+1} \leq \ldots$ and $\ldots \leq g y_{n+1} \leq$ $g y_{n} \leq \ldots \leq g y_{1} \leq g y_{0}$. It follows from the assumptions (a) and (b) that $g x_{n} \leq x_{*}$ and $y_{*} \leq$ 
$g y_{n}$ for all $n \in \mathbb{N}$. In addition, without loss of generality, one can assume that $g$ is nondecreasing about the partial order $\leq$. Then $g^{2} x_{n} \leq g x_{*}$ and $g y_{*} \leq g^{2} y_{n}$ for all $n \in \mathbb{N}$, where $g^{2} z:=g(g z)$ for all $z \in X$.

Next, using (A1), we obtain

$$
\begin{aligned}
& d\left(F\left(x_{*}, y_{*}\right), g^{2} x_{n+1}\right)=d\left(F\left(x_{*}, y_{*}\right), F\left(g x_{n}, g y_{n}\right)\right) \leq \phi\left[a_{n}\right], \\
& \text { and } d\left(g^{2} y_{n+1}, F\left(y_{*}, x_{*}\right)\right)=d\left(F\left(g y_{n}, g x_{n}\right), F\left(y_{*}, x_{*}\right)\right) \leq \phi\left[b_{n}\right]
\end{aligned}
$$

where

$$
\begin{aligned}
& a_{n}=b_{n}=\max \left\{d\left(g x_{*}, g^{2} x_{n}\right), d\left(y_{*}, g^{2} y_{n}\right), d\left(g x_{*}, F\left(x_{*}, y_{*}\right)\right),\right. \\
& d\left(g y_{*}, F\left(y_{*}, x_{*}\right)\right), d\left(g^{2} x_{n}, g^{2} x_{n+1}\right), d\left(g^{2} y_{n}, g^{2} x_{n+1}\right), \\
& \left.\frac{d\left(g x_{*}, g^{2} x_{n+1}\right)+d\left(g^{2} x_{n}, F\left(x_{*}, y_{*}\right)\right)}{2}, \frac{d\left(g y_{*}, g^{2} y_{n+1}\right)+d\left(g^{2} y_{n}, F\left(y_{*}, x_{*}\right)\right)}{2}\right\} .
\end{aligned}
$$

Now, we claim that

$$
\max \left\{d\left(g x_{*}, F\left(x_{*}, y_{*}\right)\right), d\left(g y_{*}, F\left(y_{*}, x_{*}\right)\right)\right\}=0 .
$$

If this not true, then $\max \left\{d\left(g x_{*}, F\left(x_{*}, y_{*}\right)\right), d\left(g y_{*}, F\left(y_{*}, x_{*}\right)\right)\right\}>0$. Since $\lim _{n \rightarrow \infty} g x_{n}=$ $x_{*}, \lim _{n \rightarrow \infty} g y_{n}=y_{*}$, there exists $N \in \mathbb{N}$ such that for all $n>N$,

$$
a_{n}=b_{n}=\max \left\{d\left(g x_{*}, F\left(x_{*}, \gamma_{*}\right)\right), d\left(g \gamma_{*}, F\left(y_{*}, x_{*}\right)\right)\right\} .
$$

Combining this with (2.8) and (2.9), we get for all $n>N$,

$$
\begin{aligned}
& \max \left\{d\left(F\left(x_{*}, y_{*}\right) g^{2} x_{n+1}\right), d\left(g^{2} y_{n+1}, F\left(y_{*}, x_{*}\right)\right)\right\} \\
\leq & \phi\left[\max \left\{d\left(g x_{*}, F\left(x_{*}, y_{*}\right)\right), d\left(g \gamma_{*}, F\left(y_{*}, x_{*}\right)\right)\right\}\right] .
\end{aligned}
$$

Letting $n \rightarrow \infty$ it follows that

$$
\begin{gathered}
\max \left\{d\left(g x_{*}, F\left(x_{*}, y_{*}\right)\right), d\left(g y_{*}, F\left(y_{*}, x_{*}\right)\right)\right\} \\
\leq \phi\left[\max \left\{d\left(g x_{*}, F\left(x_{*}, y_{*}\right)\right), d\left(g y_{*}, F\left(y_{*}, x_{*}\right)\right)\right\}\right] .
\end{gathered}
$$

This is a contradiction. So (2.10) holds. Then, it follows that $g x_{*}=F\left(x_{*}, y_{*}\right)$ and $g y_{*}=$ $F\left(y_{*}, x_{*}\right)$.

Remark 1. It is easy to see that Theorems 2.1. and 2.2. are generalizations of corresponding results in [7]. In addition, Theorems 2.1. and 2.2. extends some earlier results for non-decreasing mappings in partially ordered metric spaces. For example, let $g=I$ (the identity map), $F$ be non-decreasing under the first argument and be independent of the second argument, one can deduce [2, Theorem 2.2].

In some cases, one can show that the coupled coincidence point is a coupled common fixed point. For example, we have the following result:

Theorem 2.3. Suppose all the assumptions of Theorem 2.1. (or Theorem 2.2.) are satisfied. Moreover, assume that

(A4) the $M_{F, g}(x, y, u, v)$ in (A1) equals to

$$
\max \left\{d(g x, g u), d(g y, g v), \frac{d(g x, F(u, v))+d(g u, F(x, y))}{2}, \frac{d(g y, F(v, u))+d(g v, F(y, x))}{2}\right\} ;
$$


(A5) for every $\left(x_{1}, x_{2}\right),\left(y_{1}, y_{2}\right) \in X \times X$, there exists $\left(z_{1}, z_{2}\right) \in X \times X$ such that $\left(g z_{1}\right.$, $\left.g z_{2}\right)$ is comparable to $\left(g x_{1}, g x_{2}\right)$ and $\left(g y_{1}, g y_{2}\right)$.

Then $F$ and $g$ have a unique coupled common fixed point, i.e., there exists a unique $(a, b) \in X \times X$ such that $F(a, b)=g a=a$ and $F(b, a)=g b=b$.

Proof. By Theorem 2.1. (or Theorem 2.2.), we know that $F$ and $g$ have a coupled coincidence point, i.e., there exist $x_{*}, y_{*} \in X$ such that $F\left(x_{*}, y_{*}\right)=g x_{*}$ and $F\left(y_{*}, x_{*}\right)=$ gy. Let $\left(x^{*}, y^{*}\right) \in X \times X$ be also a coupled coincidence point of $F$ and $g$. First, let us prove that

$$
g x_{*}=g x^{*}, g y_{*}=g y^{*} .
$$

By (A5), there exists $\left(u_{0}, v_{0}\right) \in X \times X$ such that $\left(g u_{0}, g v_{0}\right)$ is comparable to $\left(g x_{*}, g y_{*}\right)$ and $\left(g x^{*}, g y^{*}\right)$. Let

$$
g u_{n}=F\left(u_{n-1}, v_{n-1}\right), g v_{n}=F\left(v_{n-1}, u_{n-1}\right), n=1,2, \ldots
$$

Since $F$ is mixed $g$-monotone and $\left(g u_{0}, g v_{0}\right)$ is comparable to $\left(g x_{*}, g y_{*}\right)$, we claim that $\left(F\left(u_{0}, v_{0}\right), F\left(v_{0}, u_{0}\right)\right)$ is comparable to $\left(F\left(x_{*}, y_{*}\right), F\left(y_{*}, x_{*}\right)\right)$, i.e., $\left(g u_{1}, g v_{1}\right)$ is comparable to $\left(g x_{*}, g y_{*}\right)$. In fact, if

$$
\left(g u_{0}, g v_{0}\right) \leq\left(g x_{*}, g y_{*}\right),
$$

i.e.,

$$
g u_{0} \geq g x_{*} \text { and } g v_{0} \leq g y_{*}
$$

and thus

$$
g u_{1}=F\left(u_{0}, v_{0}\right) \geq F\left(x_{*}, y_{*}\right)=g x_{*} \text { and } g v_{1}=F\left(v_{0}, u_{0}\right) \leq F\left(y_{*}, x_{*}\right)=g y_{* \prime}
$$

which means that

$$
\left(g u_{1}, g v_{1}\right) \leq\left(g x_{*}, g y_{*}\right) ;
$$

if $\left(g u_{0}, g v_{0}\right)=\left(g x_{*}, g y_{*}\right)$, by a similar proof, we can get $\left(g u_{1}, g v_{1}\right) \geq\left(g x_{*}, g y_{*}\right)$. In addition, analogously to the above proof, one can also show that $\left(g u_{1}, g v_{1}\right)$ is comparable to $\left(g x^{*}, g y^{*}\right)$. Hence, by induction, one can prove that for each $n \in \mathbb{N},\left(g u_{n}, g v_{n}\right)$ is comparable to $\left(g x_{*}^{*}, g y_{*}\right)$ and $\left(g x^{*}, g y^{*}\right)$.

Now, by (A4), we have

$$
\begin{aligned}
& \max \left\{d\left(g x_{*}, g u_{n+1}\right), d\left(g y_{*}, g v_{n+1}\right)\right\} \\
= & \max \left\{d\left(F\left(x_{*}, \gamma_{*}\right), F\left(u_{n}, v_{n}\right)\right), d\left(F\left(\gamma_{*}, x_{*}\right), F\left(v_{n}, u_{n}\right)\right)\right\} \leq \phi\left[c_{n}\right],
\end{aligned}
$$

where

$$
c_{n}=\max \left\{d\left(g x_{*}, g u_{n}\right), d\left(g \gamma_{*}, g v_{n}\right), \frac{d\left(g x_{*}, g u_{n+1}\right)+d\left(g x_{*}, g u_{n}\right)}{2}, \frac{d\left(g \gamma_{*}, g v_{n+1}\right)+d\left(g y_{*}, g v_{n}\right)}{2}\right\} .
$$

We claim that $c_{n}=\max \left\{d\left(g x_{*}, g u_{n}\right), d\left(g y_{*}, g v_{n}\right)\right\}$. In fact, if $c_{n}=\frac{d\left(g x_{*}, g u_{n+1}\right)+d\left(g x_{*}, g u_{n}\right)}{2}>0$, then $d\left(g x_{*}, g u_{n+1}\right) \leq \phi\left[c_{n}\right]<\frac{d\left(g x_{*}, g u_{n+1}\right)+d\left(g x_{*} g u_{n}\right)}{2}$, which means that $d\left(g x_{*}, g u_{n+1}\right)<d\left(g x_{*}\right.$, $\left.g u_{n}\right)$, and thus $c_{n}=\frac{d\left(g x_{*}, g u_{n+1}\right)+d\left(g x_{*}, g u_{n}\right)}{2}<d\left(g x_{*}, g u_{n}\right)$. This is a contradiction. In addition, if $c_{n}=\frac{d\left(g \gamma_{*} g v_{n+1}\right)+d\left(g \gamma_{*} g v_{n}\right)}{2}>0$, one can also show that there is a contradiction. Thus we have 
$\max \left\{d\left(g x_{*}, g u_{n+1}\right), d\left(g y_{*}, g v_{n+1}\right)\right\} \leq \phi\left[\max \left\{d\left(g x_{*}, g u_{n}\right), d\left(g y_{*}, g v_{n}\right)\right\}\right]$.

Then, it follows that

$$
\begin{gathered}
\max \left\{d\left(g x_{*}, g u_{n+1}\right), d\left(g \gamma_{*}, g v_{n+1}\right)\right\} \\
\leq \phi^{n+1}\left[\max \left\{d\left(g x_{*}, g u_{0}\right), d\left(g \gamma_{*}, g v_{0}\right)\right\}\right] .
\end{gathered}
$$

Analogously to the above proof, one can also show that

$$
\max \left\{d\left(g x^{*}, g u_{n+1}\right), d\left(g y^{*}, g v_{n+1}\right)\right\} \leq \phi^{n+1}\left[\max \left\{d\left(g x^{*}, g u_{0}\right), d\left(g y^{*}, g v_{0}\right)\right\}\right] .
$$

Letting $n \rightarrow \infty$, we get $g x_{*}=\lim _{n \rightarrow \infty} g u_{n+1}=g x^{*}, g y^{*}=\lim _{n \rightarrow \infty} g v_{n+1}=g y^{*}$.

Since $F\left(g x_{*}, g y_{*}\right)=g\left(g x_{*}\right)$ and $F\left(g y_{*}, g x_{*}\right)=g\left(g y_{*}\right),\left(g x_{*}, g y_{*}\right)$ is a coupled coincidence point of $F$ and $g$, thus, by (2.11), we have $g\left(g x_{*}\right)=g x_{*}, g\left(g y_{*}\right)=g y_{*}$. Let $a=g x_{*}$ and $b=$ $g y_{*}$. Then $F(a, b)=F\left(g x_{*}, g y_{*}\right)=g\left(g x_{*}\right)=g a=a$ and $F(b, a)=F\left(g y_{*}, g x_{*}\right)=g\left(g y_{*}\right)=$ $g b=b$. It remains to show the uniqueness. Let $(c, d) \in X \times X$ such that $F(c, d)=g c=$ $c$ and $F(d, c)=g d=d$. Since $(a, b)$ and $(c, d)$ are both coupled coincidence points of $F$ and $g$, by (2.11), we get $g a=g c, g b=g d$, and thus $a=c, b=d$. This completes the proof.

\section{Acknowledgements}

The authors thank the referees for their valuable comments that helped to improve the text. Hui-Sheng Ding acknowledges support from the NSF of China (11101192), the Key Project of Chinese Ministry of Education (211090), the NSF of Jiangxi Province (20114BAB211002), the Jiangxi Provincial Education Department (GJJ12173), and the Program for Cultivating Youths of Outstanding Ability in Jiangxi Normal University. Third author is thankful to the Ministry of Science and Technology Development of Serbia.

\section{Author details}

${ }^{1}$ College of Mathematics and Information Science, Jiangxi Normal University, Nanchang, Jiangxi 330022, People's Republic of China ${ }^{2}$ Faculty of Mechanical Engineering, University of Belgrade, Kraljice Marije 16, 11120 Belgrade, Serbia

\section{Authors' contributions}

All authors contributed equally and significantly in writing this paper. All authors read and approved the final manuscript.

\section{Competing interests}

The authors declare that they have no competing interests.

Received: 21 January 2012 Accepted: 12 June 2012 Published: 12 June 2012

\section{References}

1. Ran, ACM, Reurings, MCB: A fixed point theorem in partially ordered sets and some application to matrix equations. Proc Am Math Soc. 132, 1435-1443 (2004). doi:10.1090/S0002-9939-03-07220-4

2. Agarwal, RP, El-Gebeily, MA, O'Regan, D: Generalized contractions in partially ordered metric spaces. Appl Anal. 87, 109-116 (2008). doi:10.1080/00036810701556151

3. Kadelburg, Z, Pavlović, M, Radenović, S: Common fixed point theorems for ordered contractions and quasicontractions in ordered cone metric spaces. Comput Math Appl. 59, 3148-3159 (2010). doi:10.1016/j.camwa.2010.02.039

4. Long, W, Rhoades, BE, Rajović, M: Coupled coincidence points for two mappings in metric spaces and cone metric spaces. Fixed Point Theory Appl. 2012, 66 (2012). doi:10.1186/1687-1812-2012-66

5. Nieto, JJ, Lopez, RR: Contractive mapping theorems in partially ordered sets and applications to ordinary differential equations. Order.22, 223-239

6. O'Regan, D, Petrusel, A: Fixed point theorems for generalized contractions in ordered metric spaces. J Math Anal Appl. 341, 1241-1252 (2008). doi:10.1016/j.jmaa.2007.11.026

7. Gnana Bhaskar, T, Lakshmikantham, V: Fixed point theorems in partially ordered metric spaces and applications. Nonlinear Anal. 65, 1379-1393 (2006). doi:10.1016/j.na.2005.10.017

8. Abbas, M, Ali Khan, M, Radenović, S: Common coupled fixed point theorems in cone metric spaces for w-compatible mappings. Appl Math Comput. 217, 195-202 (2010). doi:10.1016/j.amc.2010.05.042

9. Abbas, M, Nazir, T, Radenović, S: Common fixed points of four maps in partially ordered metric spaces. Appl Math Lett. 24, 1520-1526 (2011). doi:10.1016/j.aml.2011.03.038

10. Aydi, H, Postolache, $M$, Shatanawi, W: Coupled fixed point results for $(\boldsymbol{\psi}, \boldsymbol{\nabla})$-weakly contractive mappings in ordered $\mathrm{G}$ metric spaces. Comput Math Appl. 63, 298-309 (2012). doi:10.1016/j.camwa.2011.11.022

11. Aydi, H, Karapinar, E, Shatanawi, W: Coupled fixed point results for $(\boldsymbol{\psi}, \mathbb{\nabla})$-weakly contractive condition in ordered partial metric spaces. Comput Math Appl. 62, 4449-4460 (2011). doi:10.1016/j.camwa.2011.10.021 
12. Cho, YJ, Rhoades, BE, Saadati, R, Samet, B, Shatanawi, W: Nonlinear coupled fixed point theorems in ordered generalized metric spaces with integral type. Fixed Point Theory Appl. 2012, 8. doi:10.1186/1687-1812-2012-8 (2012)

13. Lakshmikantham, V, Cirić, L: Coupled fixed point theorems for nonlinear contractions in partially ordered metric spaces. Nonlinear Anal. 70, 4341-4349 (2009). doi:10.1016/..na.2008.09.020

14. Nashine, HK, Shatanawi, W: Coupled common fixed point theorems for a pair of commuting mappings in partially ordered complete metric spaces. Comput Math Appl. 62, 1984-1993 (2011). doi:10.1016/j.camwa.2011.06.042

15. Shatanawi, W: Fixed point theorems for nonlinear weakly C-contractive mappings in metric spaces. Math Comput Model 54, 2816-2826 (2011). doi:10.1016/j.mcm.2011.06.069. doi:10.1016/j.mcm.2011.06.069

16. Shatanawi, W, Samet, B, Abbas, M: Coupled fixed point theorems for mixed monotone mappings in ordered partial metric spaces. Math Comput Model. 55, 680-687 (2012). doi:10.1016/j.mcm.2011.08.042

17. Choudhury, BS, Kundu, A: A coupled coincidence point result in partially ordered metric spaces for compatible mappings. Nonlinear Anal. 73, 2524-2531 (2010). doi:10.1016/j.na.2010.06.025

18. Samet, B: Coupled fixed point theorems for a generalized Meir-Keeler contraction in partially ordered metric spaces. Nonlinear Anal. 72, 4508-4517 (2010). doi:10.1016/j.na.2010.02.026

doi:10.1186/1687-1812-2012-96

Cite this article as: Ding et al: Coupled coincidence point theorems for generalized nonlinear contraction in partially ordered metric spaces. Fixed Point Theory and Applications 2012 2012:96.

\section{Submit your manuscript to a SpringerOpen ${ }^{\odot}$} journal and benefit from:

- Convenient online submission

- Rigorous peer review

- Immediate publication on acceptance

- Open access: articles freely available online

- High visibility within the field

- Retaining the copyright to your article

Submit your next manuscript at $\gg$ springeropen.com 